\title{
The adverse effect of bromelin in anti-D quantitation using the AutoAnalyzer
}

\author{
H. H. GUNSON, P. K. PHILlips, ${ }^{1}$ AND F. STRATTON \\ From the Regional Transfusion Service, Manchester
}

SYNOYSIS With eight of 32 sera significantly higher estimations of anti-D concentration were obtained when test cells premodified with bromelin were used instead of bromelin as a reagent added to the reaction manifold. With one serum the difference in estimation, using the two techniques, revealed a ten-fold discrepancy. The consequences of these findings are discussed in relation to the use of the AutoAnalyzer for the quantitation of anti-D.

The technique commonly used for quantitation of anti-D in the AutoAnalyzer employs bromelin solution as a reagent (Rosenfield and Haber, 1966; Moore, 1969; Judd and Jenkins, 1970; Sturgeon and Kaye, 1970), which is pumped into the reaction manifold with anti-D antiserum, test cells, and the rouleaux-inducing agent. Moore and Hughes-Jones (1970) noted that an occasional serum gave a noticeably higher concentration of anti-D when the test cells were pretreated with bromelin compared with the use of bromelin as an added reagent. Thus the possibility exists that the conditions prevailing in the reaction manifold are not those which will give maximum agglutination of $\mathrm{Rh}(\mathrm{D})$-positive test cells in every instance. Because of the basic importance of obtaining the maximum degree of agglutination for every serum analysed it was considered that this aspect of the method was worthy of further investigation.

Experiments will be described in which the concentration of anti-D has been estimated simultaneously by the use of bromelized test cells and bromelin solution added to the reaction manifold.

\section{Materials and Methods}

AUTOMATED METHODS FOR THE DETERMINATION OF ANTI-D CONCENTRATION INVOLVING THE SIMULTANEOUS USE OF TWO MANIFOLDS The basic apparatus, reagents, and method of analysis used for the quantitation of anti-D have been described (Gunson, Phillips, and Stratton, 1972). So that one antiserum can be assayed simul-

Postgraduate student, Department of Chemistry, University of Lancaster

Received for publication 31 August 1971. taneously in two manifolds a T-piece (Technicon PT2), is inserted in the line from the sampler and arranged so that the air bubble which separates the serum and wash is split at the T-piece, one half proceeding down each limb. Separate lines from each manifold are placed in the methyl cellulose, the rouleaux-dispersing, and the haemolysing agent. The residual haemoglobin from each manifold is passed through a separate colorimeter and the optical density (OD) recorded. In the experiment comparing the anti-D concentrations obtained with the use of bromelin solution and bromelized cells, described below, the washed or bromelized cells are fed into the appropriate manifold. Bromelin solution $(0.6 \%)$ is pumped into the manifold receiving washed cells and this reagent is replaced with physiological saline in the manifold receiving bromelized cells.

Preliminary experiments were carried out to ensure that the results obtained for either of the above methods did not significantly differ between the two manifolds. Using bromelin as an added reagent in both manifolds, 128 dilutions of sera were assayed simultaneously using seven different test cells. The comparisons were made on seven days spread over several weeks, during which time the pump tubes were changed and different preparations of reagents were used. Similarly, 72 determinations of anti-D concentration were carried out using four different bromelized test cells. From each series of tests the difference (d) between each pair of results, expressed as a percentage of the average for that pair, was subjected to Student's t test, using a computer, assuming the null hypothesis that there is no difference in the estimations from the two manifolds. For the results with bromelin as a reagent $t=0.455$ for 127 degrees of freedom, ie, $0.6<2 \alpha<0.7$ with 
a variance of $57.8 \%$, and for the results with bromelized cells $t=0.111$ for 71 degrees of freedom, ie, $0.90<2 \alpha<0.95$, with a variance of $46.1 \%$.

It is concluded that there is no significant difference between the estimates of anti-D concentration from the simultaneous use of two manifolds with either method. Moreover, from the variance ratio test, the variances are homologous. From the best estimate of variance the standard deviation is $7.3 \%$ for 198 degrees of freedom, ie, $95 \%$ of results will lie within $\pm 14 \%$ and $99.5 \%$ within $\pm 21 \%$.

\section{CALIBRATION OF THE WORKING STANDARD}

WITH BROMELIZED TEST CELLS

The working standard consisted of a pool of 28 anti$D$ antisera and was calibrated against the International Standard for anti- $\mathrm{Rh}_{0}$ (anti-D) incomplete blood typing serum (Goldsmith, Mourant, and Bangham, 1967) as previously described (Gunson et al, 1972) except that dilutions were prepared using an automatic pipette and the tests were done on six days using three different bromelized test cells. A total of 52 estimations of the working standard were obtained and the mean concentration was found to be 21.3 iu per $\mathrm{ml}$ with a standard deviation of 1.4 iu per ml. Thus $95 \%$ of results will lie within \pm 2.9 iu per $\mathrm{ml}$ (ie, $\pm 14 \%$ ). This compares with the value of $22.3 \pm 5.9$ iu per ml determined for this standard when bromelin is added as a reagent and manual dilutions are used. It was concluded that, although the mean concentration in each instance is similar, the use of the automatic pipette is responsible for the improved $95 \%$ confidence limits, which are the same as those obtained in the investigation of serum DUG described previously (Gunson et al, 1972), and that the concentration of $21.3 \mathrm{iu}$ per ml probably reflects the correct concentration of the working standard. It was decided, therefore, to assign this value to the standard for all subsequent tests.

\section{TEST CELLS AND ANTI-RH ANTISERA}

Group $O R_{1} R_{1}$ test cells were used within five days of their collection.

Bromelized test cells are prepared using 1.0\% bromelin in a solution containing $90 \%$ physiological saline and $10 \%$ Sorensen's phosphate buffer, $0 \cdot 1 \mathrm{M} p \mathrm{H}$ 5.5. The cells are washed four times with physiological saline and packed by centrifugation. Equal volumes of $1.0 \%$ bromelin solution and packed test cells are mixed thoroughly and incubated at $37^{\circ} \mathrm{C}$ for a total time of 10 minutes with constant agitation. The treated cells are washed, without delay, using three changes of physiological saline and a $20 \%$ suspension is prepared as recommended by Marsh, Nichols, and Jenkins (1968).
Anti-Rh sera, all of which contained anti-D and some anti-G and/or anti-E, were obtained from nine females isoimmunized by $\mathrm{Rh}$ hetero-specific pregnancy, and from $23 \mathrm{Rh}(\mathrm{D})$-negative males immunized with group $\mathbf{O} \mathbf{R}_{\mathbf{2}} \mathbf{R}_{\mathbf{2}}$ cells. Samples from the males were collected at various stages of the immune response, ie, during the primary phase of antibody formation after a single stimulus, or after one or more further injections of the Rh-positive cells. Only one sample from each individual was tested.

\section{Results}

The working standard and 32 anti-D antisera, whose optimal dilution ranged from 1 in 5 to 1 in 20000 , were simultaneously applied to two manifolds using the T-piece. In one manifold, cells premodified with bromelin were used and bromelin solution was added as a reagent to the other. The estimation of anti-D concentration by each method was carried out with reference to the corresponding standard graph. The test cells in both manifolds were derived

\begin{tabular}{|c|c|c|c|}
\hline \multirow{2}{*}{$\begin{array}{l}\text { Serum } \\
\text { No. }\end{array}$} & \multicolumn{2}{|c|}{ Anti-D Concentration (iu per $m l$ ) } & \multirow{2}{*}{$\begin{array}{l}\text { Percentage } \\
\text { Difference } \\
(d)^{1}\end{array}$} \\
\hline & Bromelin Added & Bromelized Cells & \\
\hline 1 & 138 & 144 & -4 \\
\hline 2 & $14 \cdot 6$ & $12 \cdot 2$ & +18 \\
\hline 3 & $12 \cdot 3$ & $14 \cdot 4$ & -16 \\
\hline 4 & $46 \cdot 4$ & 40.4 & +14 \\
\hline 5 & $29 \cdot 0$ & $26 \cdot 8$ & $\begin{array}{r}8 \\
+\quad 8\end{array}$ \\
\hline 6 & 268 & 246 & +9 \\
\hline 7 & 0.219 & 0.213 & +3 \\
\hline 8 & 0.251 & $0 \cdot 237$ & +6 \\
\hline 9 & 0.122 & 0.158 & $-25^{2}$ \\
\hline 10 & $8 \cdot 82$ & $13 \cdot 7$ & $-45^{2}$ \\
\hline 11 & $0 \cdot 144$ & 0.118 & +20 \\
\hline 12 & 108 & 132 & -20 \\
\hline 13 & 0.117 & 0.168 & $-3 \epsilon^{2}$ \\
\hline 14 & 3.29 & 3.60 & -9 \\
\hline 15 & 14.6 & 16.4 & -12 \\
\hline 16 & 79.2 & $97 \cdot 5$ & -21 \\
\hline 17 & $5 \cdot 70$ & 8.45 & $-39^{2}$ \\
\hline 18 & 0.069 & 0.059 & +16 \\
\hline 19 & 0.237 & $0 \cdot 278$ & -16 \\
\hline 20 & $4 \cdot 48$ & $4 \cdot 60$ & $-26^{2}$ \\
\hline 21 & 3.88 & 3.68 & +5 \\
\hline 22 & 0.558 & $1 \cdot 20$ & $-68^{2}$ \\
\hline 23 & 0.632 & 0.544 & +14 \\
\hline 24 & $8 \cdot 60$ & 10.0 & -15 \\
\hline 25 & 16.4 & 16.0 & +3 \\
\hline 26 & $24 \cdot 2$ & 20.4 & +17 \\
\hline 27 & $1 \cdot 22$ & $12 \cdot 2$ & $-164^{2}$ \\
\hline 28 & $15 \cdot 5$ & 18.9 & -19 \\
\hline 29 & $22 \cdot 4$ & $20 \cdot 6$ & +8 \\
\hline 30 & $87 \cdot 6$ & 106 & -19 \\
\hline 31 & $45 \cdot 8$ & $38 \cdot 7$ & +17 \\
\hline 32 & $8 \cdot 12$ & 15.0 & $-59^{2}$ \\
\hline
\end{tabular}

Table Simultaneous estimation of the concentration of anti- $D$ using bromelin added as a reagent and bromelized cells

${ }^{1} \mathrm{~d}=$ difference between result for added bromelin and bromelized cells expressed as a percentage of the average for that pair, rounded to the nearest integer.

'd $>3$ standard deviations (see text). 
from the same donor. The results are shown in the Table.

For each pair of estimations the difference (d) between the result obtained using bromelin as a reagent and that for bromelized cells was calculated and expressed as a percentage of the average result for that pair of estimations. Those values of (d) which are negative represent a greater estimation of anti-D with bromelized test cells, viz, for serum 27,

anti- $\mathrm{D}$ concentration, bromelin added $=$

$$
1.22 \text { iu per } \mathrm{ml}
$$

anti-D concentration, bromelized cells $=$

$$
12 \cdot 2 \text { iu per } \mathrm{ml}
$$

average anti-D diference $=-10.98$

$$
\begin{aligned}
\text { difference }(d) & =\frac{-10.98 \times 100}{6.71} \\
= & -163.63 .
\end{aligned}
$$

The differences (d) before rounding to the nearest integer were subjected to a t test, assuming the null hypothesis of a true mean difference (d) of zero, $t=2.27$ for 31 degrees of freedom, ie, $0.025<2 \alpha<$ 0.05 . One cannot accept the null hypothesis and thus the two methods are producing results that are, on the whole, significantly different.

With the simultaneous use of two manifolds to compare the estimation of anti-D concentration of paired results from the same antiserum, using either bromelized cells or with bromelin added as a reagent, it was shown that $95 \%$ of the differences calculated in the same manner as those above will lie within $\pm 14 \%$ and $99.5 \%$ within $\pm 21 \%$. Reference to the Table shows that the difference (d) for eight results (marked ${ }^{2}$ ) are greater than $-21 \%$. The expected frequency for (d) greater than $-21 \%$ is 1 in 400 . The probability that eight of 32 results will exceed this value is $3.2 \times 10^{-9}$, determined by Fisher's 'exact' method for $2 \times 2$ tables. Thus with these eight antisera, the two methods employed are determining different concentrations of antibody. These sera were tested at dilutions from 1 in 5 to 1 in 400 , compared with sera at dilutions of 1 in 5 to 1 in 20000 for other results.

Seven sera give difference (d) between $-14 \%$ and $-21 \%$. Although these differences do not exceed the $99.5 \%$ confidence limits one expects only 1 in 44 results to lie within this range. The difference in these frequencies is statistically significant $(P=0.0084)$. This suggests that the difference in technique affects other antisera less dramatically than those detailed above, although more work will have to be done to obtain conclusive evidence in an individual serum. Five sera gave differences (d) greater than $+14 \%$, which is not statistically significantly different from the 1 in 40 expected $(P=0.057)$. This result implies that there may be sera whose anti-D concentration is underestimated by the use of bromelized cells. Further work on this aspect is being carried out. Differences (d) between $\pm 14 \%$ lie within 2 standard deviations and could occur by chance in $95 \%$ of tests.

Tests using $R h(D)$-negative cells, with either of the two methods above, failed to show differences in OD distinguishable from the baseline.

\section{Discussion}

Satisfactory reproducibility of results indicating a precise measure of the degree of agglutination is only one aspect in the assessment of the accuracy of the method for the determination of anti-D concentration. We have shown that it is possible to improve the limits of accuracy from $\pm 26 \%$ when dilutions are prepared manually to $\pm 14 \%$ using an automatic pipette (Gunson et al, 1972). This reduction of error is more than offset by the higher estimates of anti-D concentration which are obtained with certain sera, if bromelized test cells are used instead of bromelin being added as a reagent to the manifold. From a consideration of the theory on which the method is based and the results with $\mathrm{Rh}(\mathrm{D})$-negative test cells the higher result would appear to be the better estimate. It is not surprising that the working standard gives a similar estimate of anti-D concentration by either technique since it comprises a pool of 28 antisera and individual differences will tend to be minimized.

When bromelin is added as a reagent to the manifold, conditions prevail that resemble the one-stage enzyme test, which has been found less sensitive compared with the two-stage enzyme tests for the identification and titration of $\mathbf{R h}$ antibodies (Kissmeyer-Nielson, 1964; Dybkjaer, 1965). This may be due to protease inhibitors, present in some sera, and the particular susceptibility of certain antibody immunoglobulins to the action of proteolytic enzymes (Stratton and Renton, 1958; Natvig, Kunkel, and Gedda-Dahl, 1967; Gergely, Fudenberg, and van Loghem, 1970). All the significant differences observed in our tests were the result of a higher value with the bromelized cells, indicating a reduction in antibody activity when bromelin is present. The cause of the observed discrepancies must remain a matter for conjecture at the present time. It is unlikely to be the result of protease inhibitors as we have been able to show that the concentration of anti-D was independent of the dilution at which it was estimated. Interaction of bromelin and antibody molecules, either in solution or on the sensitized cell, cannot be ruled out. Alternatively, due to differences in avidity all antibody molecules may not affect agglutination because 
the cells are insufficiently bromelized using $0.6 \%$ bromelin solution.

From a practical point of view the underestimation of anti-D concentration is important, particularly if this is being determined to predict $\mathrm{Rh}$ haemolytic disease of the newborn. Our findings may explain the comment made by Taswell and Grina (1968) that when the AutoAnalyzer value for the measurement of anti-D concentration was incorrect compared with other methods for prediction of haemolytic disease it tended to underestimate the severity of the disease in the infant. Also, if this method is used to assess anti-D sera for inclusion in pools for the preparation of anti-D immunoglobulin there may be wastage of valuable donations of sera.

It is clear that much more work must be done before the AutoAnalyzer is accepted as a convincing method for the quantitation of anti-D. Rosenfield, Berkman, Nusbacher, Dabinsky, and Kochwa (1971) have found that different sources of $\mathrm{Rh}$ antibody tend to require dissimilar numbers of antibody molecules per tested cell to support $50 \%$ agglutination, when assayed using bromelin as a reagent, and have devised a method involving sequential eluates. We do not know as yet how these findings correlate with the results described, or whether bromelized cells, although apparently superior to the use of bromelin as a reagent, will truly measure total antibody. Experiments are in progress on these aspects of anti-D quantitation in the AutoAnalyzer and will be reported at a later date.

We wish to thank Mr S. Lucas, Harris College, Preston, for the computer studies.

This work was supported by a grant from the Department of Health and Social Security.

\section{References}

Dybkjaer, E. (1965). Enzyme methods for the demonstration of incomplete antibodies. In Proceedings of the 10th Congress of the International Society of Blood Transfusion, Stockholm, 1964, pp. 1030-1035. Karger, Basle.

Gergely, J., Fudenberg, H. H., and van Loghem, E. (1970). The papain susceptibility of IgG myeloma proteins of different heavy chain subclasses. Immunochemistry, 7, 1-6.

Goldsmith, K. L. G., Mourant, A. E., and Bangham, D. R. (1967). The international standard for anti $R_{\circ}$ (anti-D) imcomplete blood-typing serum. Bull. Wld Hlth Org., 36, 435-445.

Gunson, H. H., Phillips, P. K., and Stratton, F. (1972). Manipulative and inherent errors in anti-D quantitation using the AutoAnalyzer. J. clin. Path., 25, 198-203.

Judd, W. J., and Jenkins, W. J. (1970). Assay of anti-D using the Technicon AutoAnalyser and the international standard anti-D typing serum. J. clin. Path., 23, 801-804.

Kissmeyer-Nielsen, F. (1964). The serology of 123 anti-E and 55 anti-c antibodies. Sangre (Barcelona), 9, 221-224.

Marsh, W. L., Nichols, M. E., and Jenkins, W. J. (1968). Automated detection of blood group antibodies. J. med. Lab. Technol., 25, 335-342.

Moore, B. P. L. (1969). Automation in the blood transfusion laboratory. I. Antibody detection and quantitation in the Technicon AutoAnalyser. Canad. med. Ass. J., 100, 381-387.

Moore, B. P. L., and Hughes-Jones, N. C. (1970). Automated assay of anti-D concentration in plasmapheresis donors. In Proceedings of the Technicon International Congress, 1969, pp. 281-284.

Natvig, J. B., Kunkel, H. G., and Gedda-Dahl, T., Jnr. (1967). Genetic studies on the heavy chain subgroups of $\gamma \mathrm{G}$ globulin. In Gammaglobulins (Proceedings of the 3rd Nobel Symposium), edited by J. Killander, p. 313. Interscience, New York.

Rosenfield, R. E., Berkman, E. M., Nusbacher, J., Dabinsky, C., and Kochwa, S. (1971). Immunochemistry of the Rh system. $V$. Determination of $R h$ agglutinating activity and IgG content of sequentialeluates for the assay of $\mathrm{R} h$ antibody. Transfusion, in press.

Rosenfield, R. E., and Haber, G. V. (1966). Detection and measurement of homologous human hemagglutinins. In Technicon Symposia, 1965: Automation in Analytical Chemistry, pp. 503-506. Mediad, White Plains, N.Y.

Stratton, F., and Renton, P. H. (1958). Practical Blood Grouping. Blackwell, Oxford.

Sturgeon, P., and Kaye, B. (1970). An evaluation of the single channel Auto-Analyser in the quantitation of anti $\mathrm{Rh}_{\mathrm{o}}$. Vox Sang. (Basel), 19, 14-33.

Taswell, H. F., and Grina, J. H. (1968). Evaluation of single-channel hemagglutination AutoAnalyser for antibody screening and quantitation. In Technicon Symposia, 1967: Automation in Analytical Chemistry, pp. 165-168. Mediad, White Plains, N.Y. 